\title{
Jogo DAS PERGUNTAS: \\ o Modo Operativo “AND” E o VIVER JUNTOS SEM IDEIAS ${ }^{\star}$
}

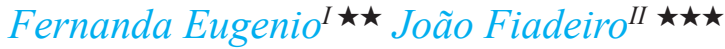 \\ ${ }^{I}$ Universidade Candido Mendes, Rio de Janeiro, RJ, Brasil / AND_Lab | Centro de Investigação \\ Artística e Criatividade Cientifica, Lisboa, Portugal \\ ${ }^{I I}$ AND_Lab $\mid$ Centro de Investigação Artística e Criatividade Científica, Lisboa, Portugal
}

\section{RESUMO}

O jogo das perguntas "como viver juntos?" e "como não ter uma ideia?" compõe o Modo Operativo AND, sistema que emergiu da contaminação recíproca entre a Composição em Tempo Real e a Etnografia como Performance Situada. No plano "como viver juntos?", o jogo tem o ritmo da improvisação coletiva em tempo real - podendo ser jogado no interior de qualquer acontecimento quotidiano ou ser praticado de modo laboratorial. No plano "como não ter uma ideia?", o jogo assume o ritmo da investigação solitária e a temporalidade da depuração: é o jogo que jogamos ao executar uma tarefa ou criar uma obra, em qualquer área de atuação. Palavras-chave: convivência; colaboração; criatividade; ética; afecto.

\section{The Question Game:}

\section{Operative Mode AND \& LIVING TOGETHER Without IDEAS}

\begin{abstract}
The question game "how to live together?" and "how to not have an idea?" composes the Operative Mode AND, a system that emerged from the reciprocal contamination between Real Time Composition and Ethnography as Situated Performance. On the "how to live together?" plan, the game has the rhythm of real time collective improvisation - it can be played within any everyday event or in laboratory practice. On the "how not to have an idea?" plan, the game takes the rhythm of a solitary research and the temporality of depuration: this is the game we play every time we work on the execution of a task or on the creation of an artcraft in any field of activity.

Keywords: togetherness; collaboration; creativity; ethics; affect.

\footnotetext{
* Subsídio da Direção Geral das Artes / Governo de Portugal e apoio da Fundação Calouste Gulbenkian. do Rio de Janeiro. Possui Pós-doutorado em Antropologia pelo Instituto de Ciências Sociais da Universidade de Lisboa. Pesquisadora Associada do Centro de Estudos Sociais Aplicados (CESAP) da Universidade Candido Mendes. Endereço: Centro de Estudos Sociais Aplicados, Universidade Candido Mendes. Rua da Assembleia, 10 - sala 824. Centro - Rio de Janeiro, RJ Brasil. CEP: 20011-901. Diretora do AND_Lab |Centro de Investigação Artística e Criatividade Científica/Portugal. Endereço: Rua Poço dos Negros 55. 1200-336 Lisboa. Portugal.

E-mail: fe.eugenio@gmail.com Científica/Portugal.

E-mail: fiadeirojoao@gmail.com
}

$\star \star$ Antropóloga. Doutora em Antropologia Social pelo Museu Nacional da Universidade Federal

$\star \star \star$ Coreógrafo. Atualmente é diretor do AND_Lab | Centro de Investigação Artística e Criatividade
\end{abstract}


O Modo Operativo AND (M.O_AND) é um sistema de ferramentas-conceito e conceitos-ferramenta de aplicabilidade transversal à arte, à ciência e ao quotidiano para a tomada de decisão, a gestão sustentável de relações e a criação de artefactos.

O M.O_AND desdobrou-se a partir do encontro entre dois modos de fazer - o do etnógrafo e o do coreógrafo. Ou, mais precisamente, a partir do encontro entre duas inquietações - a de Fernanda Eugénio com a antropologia e a de João Fiadeiro com a dança - que revelaram-se como apenas uma.

Uma: a inquietação acerca de como viver juntos, considerando que o aparato de que dispomos para isso foi todo articulado em torno da obsessão pelo separado, pelo controlo, pela esquadrinhamento, pelo saber. A inquietação acerca de como não ter uma ideia, ou seja, como prescindir desta obsessão pelo saber e pela decisão controlada, controladora ou controlável, disponibilizando-nos para tomar uma "des-cisão": entre humanos e não-humanos, sujeitos e objetos, eu e o entorno, pessoa e acontecimento, teoria e prática, pensamento e ação, agência e passividade, ética e estética e tantos dos outros opostos-complementares replicantes que sustentam a nossa visão de mundo.

O M.O_AND emergiu no quadro de um laboratório piloto de investigação, o projeto AND_Lab, onde, entre 2011 e 2012, João Fiadeiro e Fernanda Eugénio dedicaram-se à prática da des-cisão, a começar pela cisão entre teoria e prática, conceitos e ferramentas, predispondo-se a colocar num mesmo plano de uso os modos de fazer que cada um havia desenvolvido ao longo dos seus respectivos trajetos: a Composição em Tempo Real e a Etnografia Aplicada à Performance Situada.

Como consequência desta experiência piloto, além da clarificação do M.O_AND na contaminação recíproca entre os dois métodos, o AND_Lab ganhou corpo e se afirmou enquanto centro de investigação artística e criatividade científica sediado no Atelier Real, em Lisboa. O AND_Lab está estruturado à volta de dois programas: o Programa de Formação/Transmissão hANDling e o Programa de Investigação/Colaboração stANDing.

Tanto o AND_Lab como o M.O_AND funcionam de modo fractal em torno das duas perguntas-chave do nosso pensamento - "como viver juntos?" e "como não ter uma ideia?" - tornadas num jogo em espiral. Ou seja, dentro (ou fora) de cada uma delas reencontramos mais duas perguntas e, dentro (ou fora) destas, outras duas que, por sua vez, concretizam-se não por serem respondidas, mas por serem situadas. Esta operação dá-se, assim, por (des)dobramento: perante cada situação, a fim de navegarmos pelas perguntas "como", perguntamos "o quê" e "onde-quando". O quê, no que há? Como, com este quê? Onde-quando, com este como?

Como consequência, chegamos à pergunta-síntese: como podemos viver "sem" ideia e "com" o que há? Esta operação desativa aquela a que estamos mais acostumados: viver "com" ideias e "sem" o que há, ou seja, em relação privilegiada com o que acreditamos, achamos ou sabemos e não com as pessoas, lugares e circunstâncias concretas que nos interpelam. 
Por meio do recurso às formas interrogativas da linguagem "como", "o quê", "onde" e "quando" - e desviando astuciosamente daquelas que mais frequentamos por hábito ("por quê" e "quem") - ativamos um modo de reencontrar, no terreno daquilo que concretamente se apresenta, as perguntas que nos importam, encarando-as com a matéria que dispomos e que a situação nos oferece, entrando em posição com a posição do que nos envolve. Entrando em "com-posição".

Todo este trabalho, por ser situado e relacional, nunca chega a um termo, a uma resposta ou verdade. E mais um funcionamento, um meio para nos tornarmos "advérbio de modo" e escaparmos, a cada vez, de sermos "sujeitos de verbo". Um caminho para a colaboração baseada na confiança, para a conjuração da competição e das certezas. Concretamente, o que desenvolvemos com o M.O AND foi um "jogo de perguntas", que pode ser jogado desde a "escala maquete" do laboratório à "escala humana" das relações quotidianas ou da criação de artefactos. Um jogo em que o obstáculo é percebido enquanto "condição" e não enquanto "condicionante". Um jogo cujas regras emergem enquanto se joga, sustentadas na "consistência" (e não na "coerência") do que se vive e do que se partilha. Um jogo que só acontece porque deixamos de nos ocupar em "saber por quê" e nos concentramos em "saborear o quê", desdobrando "a que sabe" o acontecimento.

\section{RE-PARAR E REPARAR: DO SABER AO SABOR, DO POR QUÊ AO QUÊ}

Despertar este outro modo de operar para lidar tanto com o que acontece à nossa volta enquanto matéria daquilo que nos afecta e nos põe a trabalhar, envolve abdicar da lógica do "era uma vez" e de uma relação linear com o tempo, dispondo-nos a começar (e acabar) a história pelo "meio".

Tomar o meio como lugar de trabalho não é habitual e, parecendo simples e mesmo óbvio - já que estamos sempre "a meio" ou "em meio" de qualquer coisa e viver é sempre gerúndio - tendemos antes a começar pelo "fim". Os modos operativos que mais praticamos, por diferentes que sejam, raramente partem do "fator de situação" do meio: articulam-se todos pelo fim e variam tão somente no modo como o entendem. Se o situam no futuro, colocam-nos para começar pelo "fim-finalidade": objectivo, meta ou expectativa. Se o situam no passado, colocam-nos para começar pelo "fim-causalidade": causa, origem, motivo, razão, tradição ou, aqui também, expectativa. Essa simples escolha em se começar pelo fim encerra esses modos operativos num formato-lei - a lei da expectativa, que nos põe à partida na posição de "narrar o que foi, o que é e o que será" - apoiados por algum gênero de saber ou pressuposto. Aliás, este é um outro modo de falar do mesmo problema: os jogos que estamos habituados a jogar são aqueles em que, sendo as regras dadas de antemão, as posições também são postas mesmo antes de lá estarem: na prática, não são postas, mas "pressupostas", acabando, assim, por serem também "impostas".

Em jogos desse tipo, há pouco ou nenhum espaço para aquilo que não seja esperado e sabido. O imprevisível, se e quando aparece, não consegue ativar senão o mesmo jogo do saber, e neste jogo não consegue ocupar lugar positivo: aparece quanto muito no negativo da "falta". "Falta de sentido", que nos remete 
imediatamente, não para lidar com o concreto do que o imprevisível traz consigo, mas com o abstracto do que supomos que ele nos tira, e que procuramos sem demora repor: o tal fim, o porquê nas suas infinitas gradações de finalidade ou causalidade. Nesse jogo do saber, portanto, não há espaço para o não saber: ou se sabe (o porquê) ou se procura saber (por quê?). Ou seja, resolver e responder. O jogo do saber é também o jogo da resposta: ou já a temos, e o imprevisível nem se nota, ou de súbito não a temos, pois este imprevisível intruso a rouba. E, nesse caso, há sempre algo que julgamos saber, há sempre uma resposta que ainda levamos escondida na manga: é preciso a todo o custo explicar ou interpretar, recuperar o porquê e o fio da narrativa-expectativa, devolver as coisas aos seus "devidos" e domesticados lugares.

Dizíamos que para ativar o M.O_AND é preciso começar pelo meio. Mas, em quê consiste esse trabalho, afinal? Consiste, tão simplesmente (e por isso, complexamente), em ocuparmo-nos não dos porquês, mas do "quê" que há no meio. Começar pelo meio é começar pelo imprevisível, ou melhor: começar justo aí, no imprevisível, nesse lugar-situação envolvente em que acidente e acidentado irrompem e se interrompem mutuamente, funcionando como ocasião recíproca para encontrar um novo jogo, um outro jogo. Para substituir o jogo do saber e o jogo das respostas pelo "jogo do sabor" e pelo "jogo das perguntas".

A ativação desse outro modo operativo acontece exatamente aí, justo nesse meio: o meio ambiente do encontro com o inesperado, que se acena como "janela de oportunidade" para nos desviarmos da expectativa. Nesse jogo já não é a situação em redor que ocupa o lugar daquilo que se espera, mas nós próprios é que entramos em "modo espera". O primeiro (e talvez a único) gesto do M.O AND é mesmo este: parar. Ou, melhor dizendo, "re-parar": voltar a parar lá onde o acidente irrompe e nos interrompe.

Ao sermos interpelados pelo inesperado, em qualquer escala - seja a dos grandes acidentes ou a dos pequenos imprevistos - "pôr em marcha esta paragem" consiste, portanto, em nos dispormos a suspender a reação padrão de (já) saber ou de voltar a saber e tomar = este quê ainda sem nome - sem passado para lhe dar causa ou futuro para lhe dar meta - como meio.

Logo que "re-paramos" o meio ganha relevo. Isso porque "re-parar" é também, e quase de imediato, "reparar" no que há à volta, nos fatores de situação cujas inter-relações emergem enquanto teias de um imenso e envolvente mapa vivo: diferentemente das tramas lineares das narrativas-expectativa (que operam por desenvolvimento e não por envolvimento), essas teias não fazem história mas sim geografia: operam por (des)dobramento. Estamos em pleno meio: somos o que temos e o que nos têm, nesta implicação recíproca que nos torna, junto com o acidente, simultaneamente espaço, tempo, matéria e relação. Aqui, nesse terreno, o saber de nada serve - a não ser na medida em que também tem, como tudo o que lá está, matéria passível de ser trabalhada. Saber não permite reparar, mas apenas "olhar" (operação de constatação do porquê) ou "ver" (a operação de interpreta- 
ção do porquê). Mas, quando aguentamos "ficar no meio", quando aguentamos não saber, eis que o reparar se ativa: já não há uma procura por respostas, mas uma navegação pelas perguntas que a teia de relações ali presentes nos oferece.

Não mais "saber porque é", mas "saborear o quê há".

Reparar e saborear consistem numa experiência imediatamente junto ao "quê" que lá está. Enquanto a operação do olhar/ver/saber, produz separação e cisão entre o sujeito (do conhecimento-narrativa) e o objeto (que é conhecido-narrado), reparar/saborear só se "realiza" (no duplo aspecto de tomar lugar e dar-se conta do lugar) como ato de aproximação, contacto, relação: como ato de des-cisão. É no "juntos" que se re-para e repara.

E para que o reparar e o saborear tenham lugar enquanto "modo de fazer" e enquanto "como", é preciso, antes de mais, não responder a este "como". Pois ao perguntar "como" - Como viver juntos? Como não ter uma ideia? - corremos sempre o (sério) risco de responder e assim nos vermos reenviados para o jogo do saber. Daí a tática: a cada pergunta, uma re-pergunta.

No âmbito do M.O_AND, se a nossa primeira e única pergunta é o "como", o nosso trabalho é (des)dobrar esta pergunta em outras perguntas que se interrogam, e se voltam a perguntar.

\section{As Ferramentas-Conceito do M.O_AND E o JOGo DA PERgunta "COMO VIVER JUNTOS?"}

O jogo começa quando nos deixamos apanhar pelo imprevisível. Se quisermos ser rigorosos em tomar a vida na sua condição de "constante inconstância" acidentada, o jogo poderia, então, virtualmente, começar a cada instante e em qualquer momento. Mas o acidente só se cumpre como tal na medida em que é "usado"; por isso, para que o jogo comece é preciso fazer do imprevisível uma "zona de atenção", um lugar de encontro em potência: não basta que o acidente nos interrompa, é preciso que reparemos nessa interrupção.

No âmbito da investigação do M.O_AND, dispomos de dois espaços-modulações para acionar este acidente-encontro, a partir dos terrenos de prática da dança e da antropologia. Por um lado, temos o espaço laboratorial concedido pelo dispositivo atelier/estúdio; por outro lado, podemos trabalhar no plano da "vida vivida" tomada como campo etnográfico.

O laboratório permite-nos acionar aquilo a que chamamos "escala maquete", enquanto o trabalho de campo dá-nos acesso ao jogo à "escala humana". Essas "escalas" correspondem a diferentes cortes fractais, que, entretanto, operam do mesmo modo no que se refere ao seu funcionamento. O "modo" como nos implicamos e o ativar do trabalho de re-parar e reparar ativa, ao mesmo tempo, seja em que escala for, um viver da vida - negociação permanente com a imprevisibilidade - e um laboratório de investigação do viver juntos. 
A diferença entre a maquete e o trabalho em campo, a haver, estará no modo como a "zona de atenção" - o intervalo entre a manifestação e a percepção do evento imprevisto que funciona como ponto de partida para o jogo das perguntas - irrompe e se instala. Enquanto na escala humana dos acontecimentos quotidianos o "enquadrar" do evento pela nossa percepção acontece a meio e no meio de qualquer coisa, na escala maquete do laboratório é necessário esperar pela primeira tomada de posição de um dos "jogadores" para que o acidente irrompa para os demais. Essa Primeira Posição inaugura a com-posição colectiva, por meio do desdobrar de uma "regulação imanente" e comum. Como em qualquer processo de improvisação, uma vez instalada a Primeira Posição, na vida ou no estúdio, ninguém controla de antemão o que cada "jogador/agente" fará, nem o que será feito do que cada um faz. Mas, ao contrário de uma improvisação tradicional, cujo código passa em grande medida pela liberdade individual arbitrária - ao ponto de raras vezes se chegar a jogar "com" alguém, sendo o resultado mais comum a soma de um conjunto de propostas contíguas, mas não coexistentes - cada posição, nesse caso, é tomada em relação com as "propriedades-possibilidades" da posição precedente (após a primeira posição) e da relação precedente (após a segunda posição). Esse procedimento não é mais do que uma tática para "nos protegermos de nós próprios". Só assim a partilha deixa de ter um sentido-significado, para passar a ter um sentido-direção.

Quando jogamos o "jogo do saber", o "comum” é pensado enquanto código pré-existente (e, de preferência, consensual): para se jogar precisamos saber um conjunto de regras e, em seguida, reproduzi-las. Quando nos dispomos a jogar o "jogo do sabor", o primeiro trabalho é "encontrar o jogo" (ou a direção comum) a partir do que temos e de onde estamos: um plano de convivência para as diferenças que trazemos para o encontro, feito dos encaixes possíveis entre elas (um plano, portanto, "dissensual"). Isso perfaz todo um primeiro trabalho em torno do viver juntos, por meio de uma entrada em com-posição negociada situacional com o colectivo.

Como nesse jogo não há regras pressupostas, esta negociação só pode ser feita com o que há (e não com o que gostaríamos que houvesse). Assim, desde logo precisamos estar atentos à temporalidade da própria situação, pois esta funciona, simultaneamente, enquanto componente e enquanto condição de tudo o que há. Ou seja, todo esse trabalho de com-posição não se pode impor como "pausa artificial", tendo, ao contrário, de encontrar tempo "dentro do próprio tempo" para se realizar. Viver juntos dá-se (ou não se dá) em "tempo real": e este não consiste numa linearidade objectiva universal, mas no tempo realizado pela emergência própria do evento, na duração da "autonomia de voo" de cada situação.

\subsection{Sensibilidade Às Condições Iniciais}

É dentro da zona de autonomia entre as posições - o intervalo temporal dentro do qual uma posição autônoma repete-se a si própria sem diferir - que podemos re-parar e reparar. É esse o tempo real que temos para aceitar o acidente, 
investigar os encaixes possíveis com aquilo que temos a oferecer e nos prontificar para retribuir. Todo um ciclo de "dar-receber-retribuir" pode caber nesse intervalo entre o sermos convocados a agir e a ação em si.

De modo a explorarmos todas as potencialidades do encontro e do próprio intervalo de modo justo, o empenho proposto pelo M.O_AND é que utilizemos este tempo para nos dedicarmos a um trabalho de des-cisão, do qual a decisão possa emergir como consequência, deixando de ser a causa das nossas ações. Esse trabalho não é senão a tarefa de reparar, deixando de lado, o quanto antes, o impulso de "já saber" ou de pretender "descobrir" o que o acidente "é" ou "quer dizer". Que gastemos esse intervalo para voltar a parar, renunciando à facilidade de tomar o entorno como um conjunto de fragmentos (partes de um código maior que lhes daria sentido) para, em alternativa, nos dedicarmos ao trabalho de "desframentação" ou "fractalização" que opera dentro da espiral "quê-como-onde-quando".

Para isso é preciso deixar de repartir o presente entre elementos subjetivos e objetivos: entre aquilo que o "eu" pensa/sente/quer/imagina e a suposta "objetividade" dos "objetos". Não se trata de listar as "propriedades" do entorno, nem as "possibilidades" de "pontos de vista". Antes, trata-se de fazer um inventário das "propriedades-possibilidades" da relação, encaixes em potência entre os relevos e tendências contingentes ali manifestos, que fazem da situação um campo de forças. Um inventário das affordances que emergem do encontro com a Primeira Posição e, dentre elas, daquelas que carreguem como tendência a "intensidade extensiva" e a "extensividade intensiva" (nem só extensividade, nem só intensidade). E reparar nas affordances não é uma reflexão separada à tomada de ação, é já uma "pensação", um colocar-se junto e "com", um "holograma" do corpo-a-corpo com o entorno, um fazer que difere de sua execução apenas em densidade, não em natureza.

Esta é a paragem-movimento que se desdobra entre a Primeira e aquela que será, ao mesmo tempo, a Segunda Posição e a Primeira Relação do jogo. Somente depois de tomada a Segunda Posição é que, retroactivamente, a Primeira Posição ganha corpo e é (contra-)efectuada, na medida em que, de todos os mundos possíveis que o encontro-acidente carrega consigo, apenas um será ativado.

\subsection{Encontrar o Jogo: o Plano Comum}

Temos então uma primeira relação entre duas posições; uma primeira com-posição. Dela, mais uma vez, emergem novas affordances, um pouco mais complexas de serem reparadas, porque já não se trata de reparar no que uma posição autônoma oferece, mas na relação entre posições autônomas, naquilo que sustentam em co-dependência, na ambiência entre elas. O nosso trabalho, aqui, é o de encontrar uma brecha para estabelecer uma relação com esta relação: a Terceira Posição será, assim, simultaneamente a Segunda Relação. "Relação de relações", o que equivale dizer: entrada em plano comum.

Se a Segunda Posição funciona como "sugestão" de um possível plano comum, a Terceira Posição tem a responsabilidade de "realizá-lo" - no duplo sentido de "dar-se conta" e "dar-lhe corpo". Assim, o encontrar do jogo - ou 
o ser encontrado pelo jogo - envolve um mínimo de três posições. E isso porque é também este o mínimo para que emerjam duas relações: uma relação (entre a Primeira e Segunda Posições) e uma relação com esta relação (entre a Terceira Posição e a Primeira Relação).

Evitar o desperdício é parte crucial da "ética da suficiência" que atravessa todo esse jogo. Fazer com o que temos e "menorizar" a pressuposição, o controle e a manipulação, substituindo-os por um posicionamento justo e pelo manuseamento atento, bem como por um modo de estar no qual os jogadores são antes de mais gamekeepers (e não autores) do acontecimento. Saem do quadro desse jogo as orientações baseadas na "competência" e na "eficiência" - modos de estar dos jogos competitivos - uma vez que aqui só se pode ganhar o que se aceita perder e só se ganha quando todos ganham.

Se são suficientes três posições e duas relações para encontrar um jogo/ plano comum, o nosso trabalho é criar as condições para que estas emerjam nesse intervalo mínimo, de modo a que possamos, o quanto antes, dar início ao jogo. Isto é: a viver juntos. E viver juntos será, no quadro da ética e dos procedimentos propostos pelo M.O_AND, tão somente "adiar o fim". Demorarmo-nos a encontrar o jogo seria adiar não o fim, mas o início - e isto é justamente o que costumamos experimentar nos "jogos do saber", que raramente chegam a saborear a experiência do "juntos".

\subsection{Jogar o Jogo: Adiar o Fim, Aceitar o Fim, Antecipar o Fim}

Uma vez encontrado o plano comum ou o sentido-direção do jogo, o "trabalho do reparar" transfere-se para uma dimensão infinitesimal. Nessa escala não se trata mais de re-parar antes de tomar uma posição, mas dentro e fora de cada uma delas. O ritmo e os tempos já estão clarificados, na cadência mesma do acontecimento comum, de modo que o trabalho "menoriza-se" no manuseamento das doses (quantidades não qualitativas) de repetição e diferença que o acontecimento "precisa" para se manter em (des)dobramento. Aí entra uma terceira modulação do reparar: para além do voltar a parar (re-parar) e do notar (reparar) das affordances, o trabalho da "reparação".

Esta reparação consiste na "repetição diferenciada". Assim, a cada nova "jogada", ao mesmo tempo que permanecemos no interior do plano comum, reposicionamo-nos através de subtis "mudanças de centro", capazes de preservar o dissenso, ou seja, a elasticidade da direção partilhada. A reparação, portanto, toma a forma de um constante "reabilitar para o uso" daquilo que temos, de modo a nos mantermos uns com os outros: "consertar" para "concertar". Para isso, é importante que essa reparação aconteça "atempadamente", sem recair num "remediar tardio". Reparar e não salvar; trabalhar pelo justo e não pela justiça; pela responsabilização e não pelo arrependimento.

Neste trabalho de "precisão" (nem menos, nem mais) e "prontidão" (nem antes, nem depois), a nossa atenção concentra-se em não nos deixarmos apanhar pelo saber, que poderia converter o plano comum em plano consensual e a pre- 
cisão do acontecimento em "necessidade", estancando o espiralar do jogo das perguntas num andar em círculos à volta da resposta. Este cuidado, crucial para a preservação da dimensão de regulação imanente do jogo, evita que as condições iniciais do encontro, que nos serviram para chegar a um sentido-direção partilhado, sejam capturadas pela máquina da explicação/interpretação e do sentido-significado, enrijecendo-se sob a forma de condicionantes. Através dele podemos nos proteger de fabricar coerência em relação ao que se passa, uma coerência que carregaria consigo, via expectativa, a fixação dos passos seguintes.

É isso "adiar o fim": adensar a consistência desse "jogar do jogo" sem que ele descambe em coerência. E, por isso mesmo, para se adiar o fim tem que se começar por "aceitar o fim". É a nossa capacidade e clareza em acolher um plano comum na sua condição de "finito" que nos protege que ele sobrevenha em lei. Pois começar a relação com a promessa ou a pretensão de um "para sempre" imposto por decreto teria como consequência restituir os velhos papéis marcados, condensar expectativas e autorizar toda a panóplia de acusações e cobranças com base num "deve ser". Bloqueamos a nossa capacidade de seguir reparando, já que restringimos a com-posição ao "limite-contorno" da lei: ao mesmo tempo que proclamamos um "infinito", o convertemos em "limitado". Por fim, as quantidades de diferença em relação tornam-se qualidades demarcadas, e as tomadas de posição deixam de ter margem de manobra para repetir diferindo; está instalado o círculo do looping: a paragem enquanto desistência e resignação.

Adiar o fim é, por isso, um trabalho com o ilimitado, com o alargar em espiral dos "limites-tensão" da direção comum, realizando o seu prolongamento na medida da sua "meta-estabilidade". É, portanto, um trabalho com o "finito": dentro do ciclo de vida ou do espaço-tempo de autonomia da situação. A clareza da finitude é o que permite o envolvimento responsável no manuseamento daquilo que se tem e o compromisso em comparecer de modo atempado e justo. Essa clareza é também o instrumento que possibilita a prática concreta da suficiência, trabalhando para que o fim não se consuma na vertigem do descarte e do desperdício, mas se alargue em duração.

Mas, para adiar o fim, não basta aceitá-lo. O "jogar do jogo" na duração é feito também e em simultâneo a um outro movimento imóvel: o de se "antecipar o fim". Este trabalho antecipatório nada tem que ver com precipitação, antes o contrário. Consiste no alargamento e na distribuição da atenção entre aquilo que se realiza - a complexidade da duração e a densificação da relação - e o conjunto de possíveis e impossíveis, a cada vez que não para de se atualizar. "Antecipar o fim" envolve um empenho para que a "concentração" no gamekeeping do jogo (o trabalho a ser feito no interior de cada posição) se faça acompanhar pelo "espalhamento" da clareza (o trabalho a ser feito no exterior de cada posição), de modo a que sejamos capazes de acolher e dar-nos conta dos "sinais virtuais": as quantidades de diferença ainda não efectuadas no plano comum, que desencontram dele tão somente em densidade, mas que não cessam de atravessá-lo. Interceptar os sinais, admiti-los mas sem reagir a eles de imediato: isto é antecipar o fim. Ou seja, e em última análise, antecipar o fim não é mais do que "gerir diferenças" em vez de "gerar diferenças". 
É por meio da ativação dessa atenção distribuída - awareness mais do que consciência - que podemos interceptar a diferença ainda em estado imperceptível, antes mesmo que ela tome "corpo de consequência". Essa operação permite-nos recolher em constante inventário as diferenças que emergem da repetição enquanto jogamos. Habilita-nos, também, a manusear essa matéria de diferenças emergentes, fazendo delas matéria e combustível para seguirmos juntos adiando o fim. Pois, se para seguirmos juntos precisamos preservar o plano comum, para preservar o plano comum precisamos, de quando em quando, mudar. Mudar de centro a cada jogada, mas também "mudar de plano" quando for "preciso" - no sentido de justo e não de necessário.

Sim, "adiar o fim" faz-se "aceitando o fim": não apenas admitindo o plano comum como finito mal ele se estabelece, mas também acolhendo o fim quando ele sobrevêm, por esgotamento ou saturação. Os sinais recolhidos no trabalho de antecipação indicam-nos, se estivermos atentos, a justeza da hora de parar. Se pudermos acolhê-los e fazer do próprio "ponto de situação" o critério da situação, estaremos prontos para fazer dessa hora de parar, mais uma vez, um "re-parar". Para assim fazer do fim um novo "meio", encontrar um novo início de jogo e prolongar o desejo (e não o prazer) de se viver juntos.

\section{Os CONCEITO-FERRAMENTA Do M.O_AND: COMO NÃO TER UMA IDEIA?}

O jogo da pergunta "como não ter uma ideia?" pode ser encontrado em diferentes recortes fractais no âmbito do M.O_AND. Por um lado, é "interior" ao jogo "como viver juntos?", acontecendo em tempo real no intervalo entre cada tomada de posição - é, portanto, um "jogo que se joga durante o jogo", que se desenrola em cada jogador. Por outro lado, é "anterior" ao jogo (e "posterior", pois em espiral o fim é também início), podendo aí ser descrito e vivido de diversas maneiras: amplamente falando, "não ter uma ideia" funciona como condição para se viver juntos, de modo que é este o jogo que precisamos jogar para, a cada vez, (re)aprender a oferecer aquilo que temos em relação com aquilo por que somos tidos. E esse trabalho tanto pode ser o artesanato que nos permite propor uma Primeira Posição para o jogo colectivo - na vida-laboratório ou no laboratório-vida - como pode dar lugar a um outro modo de experimentar o ato criativo individual.

O modo mais corrente pelo qual se entende a criação - seja no modelo bíblico da criação "a partir do zero", seja na concepção romântica da criação como rompante autoral - parte da ideia. Ou, melhor dizendo: restringe-se à ideia. Esta é uma das muitas vias pelas quais chegamos ao conjunto das "cisões" modernas, assim como à manutenção, como ponto cego dos nossos esquemas de vida, de alguma "transcendência" a afiançar os nossos atos. Que a execução siga a ideia, permanecendo invariavelmente aquém dela. E que a ideia surja "do nada" - para Deus ou para os deuses-indivíduos, e, especialmente, entre estes, para os deuses-autores. Com esse gênero de pressuposição, mesmo antes de fazer seja o que for, já começamos a nossa relação com o mundo em 
dívida para com a transcendência da ideia-modelo. E, nesse caso, o jogo que se aciona é de soma ou diminuição: de competição, não de cooperação, seja com o outro ou com o entorno, ambos, em algum grau, objetificados.

Por estarmos todos mais ou menos imersos nesse esquema, o jogo do "como não ter uma ideia?" envolve o mais complexo dos desafios: sermos capazes de jogar com a matéria daquilo a que chamamos "eu". De reabilitar para o "uso" aquilo que está antes desenhado para o "abuso". A complexidade dessa tarefa está no facto de que mesmo antes de começar a jogar, precisamos desfragmentar ou fractalizar este "eu" e re-encontrar enquanto "forças" aquilo que nos move enquanto "seres" - aquilo que o "esquema da ideia" já tratou de formatar em clichê: os nossos afectos e desejos. Se, para não se ter uma ideia é preciso multiplicar o "eu" dividindo-o (ou dividi-lo, multiplicando-o), fica claro que viver juntos funciona, também e reciprocamente, como condição para não se ter uma ideia. Trata-se de uma só operação, portanto, a das duas perguntas - que, entretanto, a escala na qual as jogamos (a do "eu" ou a do "grupo") não para de reformular.

Também nesse jogo começamos pelo "meio", por aquilo que nos cerca, nos atravessa e nos faz: a matéria dos nossos afectos. O "Isso" inominável que, contudo, assume forma de "Isto" a cada vez que é partilhado. E não poderia ser de outra maneira, pois a criação de um artefacto é um ato de "oferecer" - e, uma vez que "só se pode dar o que se tem", os nossos afectos são tudo o que temos (e tudo o que nos têm).

Entretanto, e antes que nos apressemos a fazer dos afectos que temos uma ideia, um projeto, uma obra a ser oferecida, convém percebermos que a relação com essa matéria dos afectos passa primeiro pela capacidade que temos de "receber" - e que a oferta da "obra" é, assim, mais um "retribuir" do que um "dar". Pois são encontros, os afectos: são, ao mesmo tempo, aquilo que temos de mais próprio e de mais alheio. E não os escolhemos, os afectos: somos encontrados por eles. De modo que, também eles são acidentes que nos interrompem de quando em vez, sob a forma de inquietação - uma inquietação que detona aquilo a que chamamos de processo criativo.

O problema é que, mal as inquietações emergem, a nossa tendência é apartarmo-nos delas - e não fazer "com" elas. Mal emergem, percebemo-las e assimilamo-las como ideias. Dito de outro modo, mal nos damos a oportunidade de conviver com o "Isso" nesta sua condição de inefável: muitas vezes, já o experimentamos via os canais dos nossos clichês, já o experimentamos como "Isto" decifrado. Não aguentamos tempo suficiente para inibir o hábito de decifrar, dizer, diagnosticar, interpretar, saber - e, assim, desativamos a hipótese de serem elas, as inquietações, que nos afectam, a nos dizerem "a que sabem". Tornadas inspiração, idealização ou modelo, amparam a nossa "intenção". E, de posse já não do afecto mas dessa "intenção", o nosso processo criativo toma o trilho da representação: obra "sobre" a ideia "implícita" e não artefacto "com" o afecto "explícito". Pior ainda: de posse dessa "intenção", já não podemos reparar na "inclinação" do terreno-afecto, no sentido-direção para o qual ele tende e nos convida. Já estamos, tão depressa, mergulhados na decifração do senti- 
do-significado pessoal que aquela inquietação nos desperta. Já estamos, tão depressa, na viagem da "ilusão biográfica", trabalhando para produzir um "efeito" a partir desse afecto que tão logo tomamos como "causa".

O problema é que os critérios pessoais da intenção só por uma feliz coincidência permitem que a "obra" funcione como ocasião de partilha, posto que a inscrevem na constelação dos códigos e significados individuais de quem a faz. De modo que, como Primeira Posição, emerge um fragmento "fechado" e "completo" em si mesmo ou, quando muito, "aberto" porque "incompleto". Em nenhum dos casos estes reúnem as condições para um posicionamento autônomo, capaz de convidar sem impor, existir sem exigir: as condições que só uma posição ao mesmo tempo "aberta" e "completa" poderiam proporcionar de modo justo. A criação que tem como único amparo e legitimação a "intencionalidade do autor" tem pouca chance de operar, desse modo, como franca e disponível zona de autonomia, ocasião para um encontro possível, ocasião para a co-dependência recíproca.

Assim, por mais "bem-intencionados" que estejamos (ou justamente por estarmos), aquilo que oferecemos tende a tomar a forma de um "fragmento independente", que dispensa o outro ou o interpela como palavra de ordem. Ao outro resta tão somente a hipótese de se posicionar diante dessa "oferta sem brechas" ou dessa "brecha sem oferta", em termos de "gosto" ou "não gosto". E, como costumamos dizer, "gostos não se discutem", de modo que, tendo o gosto como base, há poucas hipóteses de relação.

O afecto não é um gosto: enquanto este se inscreve na lógica do prazer e da satisfação, aquele desdobra-se na lógica do desejo e da inquietação. O gosto organiza-se em resposta, o afecto desorganiza-nos em pergunta. O gosto é pessoal; o afecto é transversal e, desse modo, impessoal.

Mas ,como, então, abrir uma brecha no "esquema da ideia" que nos permita trabalhar com a matéria que nos afecta, e não sobre ela? Como conjurar a ideia, esta resposta que tão rapidamente nos sobrevêm e nos põe a repetir sem diferença, com todo o conservadorismo da nossa "liberdade" de indivíduo-autor, apartando-nos de sermos muitos e de estar com muitos?

O trabalho a fazer é de "implicação" e não de "explicação".

\subsection{O Mapa do O Quê: a etnografia do encontro}

"Isso", quando emerge, é nuvem: agregado de relações de relações que nos interpela à superfície. De tão explícito, é "ób-vio", afastado e raptado da visão: com ele o mergulho da explicação/interpretação nada pode. É na superfície, portanto, que precisamos conseguir permanecer para fazer "com" ele. Enquanto ób-vio emergente, "Isso" é acidente, obstáculo, "relevo" que nos faz parar.

A primeira pergunta que nos ocorre, quando "Isso" nos acontece: "o que é Isto?" Eis a pergunta da ideia, pois quando ela nos sobrevêm a nossa tendência é saltarmos de imediato para o plano da resposta. Daí que, no âmbito do M.O AND, a proposta é simples, embora de difícil execução: primeiro, há de substituir 
este "o que é", que nos levaria a ir procurar as respostas por trás ou por baixo do que lá está - num suposto significado implícito a ser explicado - por um outro gênero de interrogação, que nos permita tactear os relevos que se "apresentam", em vez de mergulhar nas suposições daquilo que eles poderiam "representar". Em vez do ser, o haver: "o que há n'Isso, o que Isso tem, o que, n'Isso, inquieta?"

Em vez de mergulhar, navegar. Re-perguntar, reformular a pergunta, mas seguir não respondendo: eis a brecha para um trabalho que nos permite continuar no "explícito", que navegue na superfície do ób-vio sem evidenciá-lo. Trabalho de mapas, trabalho etnográfico, trabalho de reparagem. O jogo do "como não ter uma ideia?" opera numa sequência, mais uma vez espiralada, de mapa-navegação-mapa-navegação.

E como é que isso funciona? Se o nosso primeiro mapa a desenhar é um Mapa do O Quê, esta é exatamente a pergunta a não responder. Fazer o Mapa do O Quê consiste em "circunscrevê-lo" perguntando "como" e "onde-quando": "Como Isso me encontrou? Onde-quando Isso me encontrou?"

Explorar essas duas perguntas não envolve um trabalho explicativo nem interpretativo, mas descritivo. Envolve uma plena disponibilidade para "receber" o evento, para investigar as condições nas quais Isso "se deu", se ofereceu a nós. Trabalho que se situa no próprio evento como meio, território de relevos a serem re-percorridos de modo a serem circunscritos. O Mapa do O Quê tem sobretudo a responsabilidade de preservar o Isso na sua condição de "nuvem-agregado", de "envelope", "dobra", "origami”. Afinal, Isso só nos convoca porque é mesmo esta forma-força autônoma, aberta e completa como um origami: aberta, na medida em que se sustenta nas suas próprias dobras, sem cola; completa, na medida em se nos apresenta numa forma concreta, a dessas dobras. Mapear o que essa dobradura traz consigo é trabalho que se faz nas bordas: circunscrição de uma instância ou campo de forças e não a inscrição de uma substância ou campo de significado.

Ao nos implicarmos na descrição do próprio evento de emergência do Isso enquanto singularidade irrepetível, no manuseamento de uma circunscrição minuciosa do seu modo de irrupção, não fazemos outra coisa que não seja um relato de campo. Para traduzir em palavras o campo de forças do Isso, o Mapa do O Quê usa da linguagem - a mesma que costumamos nos servir para dizer a ideia - de um modo bastante particular. Chegamos assim a uma "sentença mínima", a uma "frase-tensão" capaz de descrever o Isso sob a forma de uma "operação". Desse modo, descrevemos não propriamente o afecto separado do sujeito, mas a relação entre eles, a des-cisão que faz de ambos um, e desse um, muitos.

Mapear o Quê, atingir com precisão essa descrição mínima, dá-nos acesso ao quê Isso pode e ao quê podemos fazer com Isso. Trabalhando nas bordas da dobra, circunscrevendo o entorno do encontro com Isso, transformamos a "forma" em "formulação", conjurando a hipótese de fixarmos o que Isso "é", para nos ocuparmos no que Isso "faz" e no "como isso nos faz". Essa formulação, portanto, resulta no descrever de uma operação. E essa operação, por sua vez, serve-nos como "tarefa". 
Deste modo, saímos do Mapa do O Quê não com algo a saber, mas com algo a fazer. Voltamos, assim, a estar prontos para a navegação.

Mas como navegar no Mapa do O Quê? Como efetuar a tarefa? Como operacionalizar o Isso em artefacto? A emergência mesma dessa pergunta funciona como sinal de que demos início a um novo ciclo da espiral e estamos já em pleno trabalho topográfico de mapeamento do Como.

\subsection{O Mapa do Como: o artefacto do encontro}

Do mesmo modo que o fizemos com o primeiro mapa, neste segundo mapa - o Mapa do Como - a tática será também desviarmo-nos da resposta. Uma vez clarificada a operação que nos transporta para uma tarefa de criação, temos de ter o cuidado de não nos anteciparmos em decidir como a executaremos, ou logo nos veremos devolvidos ao modo operativo da manipulação e separados da oportunidade de manusear. Portanto, mal a questão do "como executar" emerge, o nosso compromisso é distraí-la e distrairmo-nos outra vez do "eu". À pergunta "como", voltar a perguntar "o quê" e "onde-quando": "O que tenho para trabalhar? Com o que posso efetuar esta tarefa? Onde situá-la, em qual interface? Quando executá-la, qual a sua temporalidade?"

Essas perguntas dirigem-nos para um lidar com a concretude mesma do artesanato enquanto este se efetua. Mas só podemos perguntá-las honestamente, disponíveis, se não soubermos de antemão um como-fazer que já carregue consigo as suas premissas em termos de técnicas e modos, por um lado, e em termos de materialidades, "suportes" e espaços-tempos específicos, por outro. Ou seja, fazer o Mapa do Como acontece somente na medida em que somos capazes de interrogar o que "convém" à própria operação a fim de executá-la.

Viver e habitar com franqueza o Mapa do Como só é possível se, no terreno e com ele, nos dispusermos a descobrir, a cada vez, os materiais a serem acionados (palavra, corpo, imagem etc), onde os vamos situar (num teatro, numa galeria, numa interface audiovisual, fotográfica, presencial etc) e qual sua temporalidade (a do instante, a da duração, qual duração etc)

\subsection{O Mapa do Quando-Onde: A Retribuição do EnCONTRo}

Chegando aqui, não há muito mais a dizer. Estamos em plena navegação sem ideias, no corpo-a-corpo da mistura com o que temos e com o que nos têm. Eis o nosso terceiro mapa, fator de situação: o Mapa do Quando-Onde que consiste na própria tomada de posição do artefacto como espaço-tempo no qual "co-incidem" e se impessoalizam os nossos afectos e tudo o que ainda lhes é alheio. Eis uma Terceira Posição que é também Primeira, um retribuir que é também um dar, a convidar o outro e o entorno a receber e a inaugurar, uma e outra vez, o jogo do viver juntos. 


\section{REFERÊNCIAS}

Este texto, assim como o M.O_AND, foi desenhado e efectuado em com-posição com as posições que se seguem, bem como com incontáveis outras que não têm "forma de livro". Optamos por não apontar entradas de referências bibliográficas no texto, uma vez que este gênero de remissões não dá conta do modo como esses outros pensamentos aparecem no nosso: não como "fragmentos de ideias" capazes de ilustrar ou legitimar aquilo que defendemos, mas como companheiros de uma longa conversa, daquelas que já nem permitem identificar "quem disse o quê".

AGAMBEN, G. Q'est-ce qu'un dispositif? Paris: Payot \& Rivages, 2007.

AGAMBEN, G. La comunidad que viene. Valencia: Pre-textos, 2006.

ALMEIDA, M. I. M.; EUGENIO, F. Da etnografia autoral à etnografia artífice: algumas reflexões sobre o método etnográfico contemporâneo e os modos de operacionalização do encontro com o Outro. In: NICOLACI-DA-COSTA, A. M.; ROMÃO-DIAS, D. (Org.). Métodos de pesquisa qualitativa em psicologia. Rio de Janeiro: PUC-Rio. No prelo.

ALMEIDA, M. I. M.; EUGENIO, F. Autonomies Tactiques: créativité, liberátion et insertion professionelle juvénile dans Rio de Janeiro. Revue Sociétés, Paris, v. 1, n. 115, p. 7-19, 2012.

AUSTIN, J. Quando dizer é fazer. Porto Alegre: Artes Medicas, 1990.

BARTHES, R. Como viver junto. São Paulo: Martins Fontes, 2003.

BARTHES, R. Fragmentos de um discurso amoroso. Rio de Janeiro: Francisco Alves, 1991.

BARTHES, R. Le degré zero de l'écriture. Paris: Seiul, 1972.

BARTHES, R. A câmara clara. Lisboa: Edições 70, 2010.

BATESON, G. Steps to an ecology of mind. Chicago: The University of Chicago Press, 1972.

BATESON, G. Mente e Natureza: a unidade necessária. Rio de Janeiro: Francisco Alves, 1986.

BATESON, G. Naven. São Paulo: Edusp, 2008. 
BENJAMIN, W. Experiência e Pobreza. Tradução de Sérgio Paulo Rouanet. In: . Magia e Técnica, Arte e Política. 7. ed. São Paulo: Brasiliense, 1994.

Coleção Obras Escolhidas, v. 1, p. 114-119.

BENJAMIN, W. O narrador: considerações sobre a obra de Nikolai Leskov. In: . Magia e Técnica, Arte e Política. 7. ed. São Paulo: Brasiliense, 1994. Coleção Obras Escolhidas, v. 1, p. 197-221.

BERGER, J. Ways of seeing. London: Penguin Books, 1972.

BERGER, J. About looking. London: Bloomsbury, 1980.

BERGSON, H. Durée et simultanéité. Paris: PUF, 1968.

BERQUE, A; DE BIASE, A.; BONNIN, P. L'habiter dans sa poétique première. Paris: Donner Lieu, 2008.

BERQUE, A. Éloge du tetralémme. In: . Contes de Palaiseau, c. 2011. p. 1-1.

BESNIER, J. M. L’homme simplifié: le syndrome de la touché étoile. Paris: Fayard, 2012.

BLANCHOT, M. L'espace littéraire. Paris: Gallimard, 1955.

BLANCHOT, M. A conversa infinita: a palavra plural. São Paulo: Escuta, 2010.

BLANCHOT, M. La comunauté inavouable. Paris: Minuit, 1984.

BOLTANSKI, L.; CHIAPELLO, E. Le nouvel esprit du capitalisme. Paris: Gallimard, 1999.

BOURRIAUD, N. Estética Relacional. São Paulo: Martins Fontes, 2009.

BROOK, P. O espaço vazio. Lisboa: Orfeu Negro, 2008.

CALVINO, I. As cidades invisiveis. Rio de Janeiro: O Globo, 2003.

CALVINO, I. Seis propostas para o próximo milênio. São Paulo: Cia das Letras, 1991.

CAIAFA, J. A pesquisa etnográfica. In: . A aventura das cidades: ensaios e etnografias. Rio de Janeiro: FGV, 2007. p. 135-181. 
CAIAFA, J. Movimento punk na cidade: a invasão dos bandos sub. Rio de Janeiro: J. Zahar, 1985.

CANCLINI, N. G. La sociedad sin relato: antropología y estética de la inminencia. Buenos Aires/Madrid: Katz, 2010.

CHATEAU, J. Y. Le vocabulaire de Simondon. Paris: Ellipses, 2008.

CLASTRES, P. Arqueologia da violência. São Paulo: CosacNaify, 2011.

CLIFFORD, J. A experiência etnográfica. Rio de Janeiro: UFRJ, 1998.

CLIFFORD, J.; MARCUS, G. Writing Culture: the poetics and politics of ethnography. Los Angeles: University of Califórnia Press, 1986.

DAMÁSIO, A. O erro de Descartes. São Paulo: Cia. Das Letras, 2004.

DE ANDRADE, O. Pau Brasil. Paris: Sans Pareil, 1925.

DE CERTEAU, M. A invenção do cotidiano. Petrópolis: Vozes, 2004.

DELEUZE, G. Diferença e Repetição. Rio de Janeiro: Graal, 1988.

DELEUZE, G. Crítica e Clínica. Lisboa: Século XXI, 2000.

DELEUZE, G. Francis Bacon: lógica da sensação. Rio de Janeiro: J. Zahar, 2007.

DELEUZE, G. A dobra: Leibiniz e o Barroco. Campinas: Papirus, 2000.

DELEUZE, G. Lógica do sentido. São Paulo: Perspectiva, 1974.

DELEUZE, G. Conversações. São Paulo: Ed. 34, 1992.

DELEUZE, G. Bergsonismo. São Paulo: Editora 34, 2004.

DELEUZE, G. Espinosa e os signos. Porto: Rés, 1970.

DELEUZE, G. Um manifesto de menos. In: . Sobre o teatro. Rio de Janeiro: J. Zahar, 2010. p. 25-64.

DELEUZE, G. A ilha deserta. São Paulo: Iluminuras, 2006.

DELEUZE, G. A imagem-movimento: cinema 1. Lisboa: Assírio e Alvim, 2004.

DELEUZE, G. A imagem-tempo: cinema 2. São Paulo: Brasiliense, 2005. 
DELEUZE, G.; GUATTARI, F. Milles plateaux. Paris: Minuit, 1980.

DELEUZE, G.; GUATTARI, F. O que é a filosofia? São Paulo: Ed. 34, 1992.

DELEUZE, G.; GUATTARI, F. Kafka: por uma literatura menor. Lisboa: Assírio e Alvim, 2003.

DELEUZE, G.; GUATTARI, F. O Anti-Édipo. Lisboa: Assírio e Alvim, 2004.

DELEUZE, G.; PARNET, C. Dialogues. Paris: Flammarion, 1977.

ECO, U.; SEBEOK, T. O signo de três. São Paulo: Perspectiva, 1991.

EUGENIO, F. Hedonismo competente: antropologia de urbanos afetos. 2006. Tese (Doutorado)-Programa de Pós-Graduação em Antropologia Social do Museu Nacional, Universidade Federal do Rio de Janeiro, Rio de Janeiro, 2006 a.

EUGENIO, F. Corpos voláteis: consumo e cosmética de si, ou fragmentos da 'cena moderna' carioca. In: ALMEIDA, M. I. M.; EUGENIO, F. (Org.). Culturas Jovens: novos mapas do afeto. Rio de Janeiro: J. Zahar, 2006b. p. 158-176.

EUGENIO, F. Hedonismo competente: intensidade, funcionamento e modulação na 'cena carioca'. Revista Desigualdade e Diversidade, Rio de Janeiro, n. 1, p. 30-52, jul./dez. 2007a.

EUGENIO, F. Urbe-variantes: aventura e etnografia das cidades. Comunicação, Mídia e Consumo, São Paulo, v. 4, p. 143-151, 2007b.

EUGENIO, F. Uso tópico: a poética da contaminação e a dança contemporânea". OlharCE - Revista de Dança do Ceará, Fortaleza, v. 1, n. 1, p. 20-23, 2008a.

EUGENIO, F. Contemporâneo noctambulismo: ocupação urbana e fruição juvenil nas cenas eletrônicas cariocas. Revista Nuestra America, Porto, n. 5, p. 53-86, 2008b.

EUGENIO, F. Transversalidades ao Método Composição em Tempo Real de João Fiadeiro: ou algumas considerações sobre etnografia, dramaturgia e o desenho do comum. Conferência realizada no workshop [k]NOwBODY 2010a, Atelier RE.AL, Lisboa, agosto de 2010a.

EUGENIO, F. Viragem performativa, viragem etnográfica: para ativar as artes do 'como' e do 'com'. Conferencia realizada no Seminário Vozes em Performance, Festival Internacional ArtCena, Rio de Janeiro, outubro de $2010 \mathrm{~b}$. 
EUGENIO, F. Algumas notas-sensação sobre presença, presentação e operacionalização: desejando um ficar conversa; desejando adiar por tempo indeterminado a palavra assertiva. In: BARDAWIL, A. (Org.). Tecido Afetivo: por uma dramaturgia do encontro. Fortaleza: Cia. da Arte Andanças / Funarte / Ministério da Cultura, 2010c. v. 1, p. 50-53.

EUGENIO, F. O que a arte tem a ver com o que podem ser as cidades: dança, viragem etnográfica e o desenho do comum. In: PRIMO, R.; ROCHA, T. (Org.). Bienal Internacional de Dança do Ceará: um percurso de intensidades. Fortaleza: Expressão, 2011. p. 62-67.

EUGENIO, F. Criatividade situada, funcionamento consequente e orquestração do tempo nas práticas profissionais contemporâneas. In: ALMEIDA, M. I. M.; PAIS, J. M. (Org.). Criatividade e profissionalização: jovens, subjetividades e horizontes profissionais. Rio de Janeiro: J. Zahar, 2012. p. 210-258.

EUGENIO, F.; FIADEIRO, J. Secalharidade como ética e como modo de vida: o projeto And_Lab e a investigação das práticas de encontro e de manuseamento coletivo do viver juntos. Revista Urdimento, Florianópolis, v. 19, p. 61-69, 2012.

EUGENIO, F.; FIADEIRO, J. Como viver juntos: entrevista com João Fiadeiro e Fernanda Eugenio. Revista Olharce, Fortaleza, v. 2, p. 41-43, 2011.

DIDI-HUBERMAN, G. Peuples exposés, peuples figurants. Paris: Minuit, 2012.

DIDI-HUBERMAN, G. Cuando las imágenes toman posición. Madrid: A. Machado Libros, 2008.

DIDI-HUBERMAN, G. O que vemos, o que nos olha. São Paulo: Ed. 34, 1998.

FOSTER, H. The return of the Real. Cambridge: MIT, 1999.

FOSTER, H. O artista como etnógrafo. Arte \& Ensaio: Revista do Programa de Pós-Graduação em Artes Visuais - PPGAV/EBA/UFRJ, Rio de Janeiro, n. 12, p. 137-151, 2005.

FOUCAULT, M. História da sexualidade: a vontade de saber. Rio de Janeiro: Graal, 1988. v. 1.

FOUCAULT, M. Microfisica do Poder. Rio de Janeiro: Graal, 1982.

FOUCAULT, M. Isto não é um cachimbo. São Paulo: Paz e Terra, 2002.

FOUCAULT, M. As palavras e as coisas. Lisboa: Edições 70, 2005. 
GELL, A. Art and agency: an anthropological theory. Oxford: Claredon, 1998.

GELL, A. Strathernograms, or, the semiotics of mixed methaphors. In: HIRSCH, E. (Ed.). The art of anthropology: essays and diagrams. Londres/New Brunswick: Athlone, 1999. p. 29-75.

GIBSON, J. The Theory of Affordances. In: SHAW, R.; BRANSFORD, J. (Ed.). Perceiving, acting, and knowing: toward an ecological psychology. Hillsdale, NJ: Lawrence Erlbaum Associates, 1977. p. 67-82.

GIBSON, J. The ecological approach to visual perception. Boston: Houghton Mifflin, 1979.

GIL, J. Movimento total: o corpo e a dança. Lisboa: Relógio D’Água, 2001.

GIL, J. A imagem-nua e as pequenas percepções. Lisboa: Relógio D’Água, 1996.

GIL, J. O imperceptivel devir da imanência: sobre a filosofia de Deleuze. Lisboa: Relógio d’Água, 2008.

GINZBURG, C. Sinais: raízes de um paradigma indiciário. In: . Mitos, emblemas, sinais: morfologia e história. Tradução de Federico Carotti. São Paulo: Cia. Das Letras, 1989. p. 143-179.

GOLDMAN, M. Alguma antropologia. Rio de Janeiro: Relume-Dumará, 1999.

GOLDMAN, M. Formas do saber e modos do ser: observações sobre multiplicidade e ontologia no candomblé. Religião e Sociedade, v. 25, n. 2, p. 102-120, 2005.

GOLDMAN, M. Alteridade e experiência: antropologia e teoria etnográfica. Aula Ernesto Veiga de Oliveira, ISCTE/ICS, Etnográfica, Lisboa, v. 10, n. 1, p. 161-173, 2006. Disponível em: <http://ceas.iscte.pt/etnografica/docs/vol_10/N1/ Vol_x_N1_08-Goldman-AEVO.pdf>. Acesso em: 12 jan. 2013.

GOLDMAN, M. Políticas e subjetividades nos "novos movimentos culturais". Ilha R. Antr., Santa Catarina, v. 9, n. 1-2, p. 08-22, 2007. Disponível em: <https:// periodicos.ufsc.br/index.php/ilha/article/view/6315>. Acesso em: 21 dez. 2012.

GONÇALVES, J. R. S. A obsessão pela cultura. In: PAIVA, M.; MOREIRA, M. E. (Coord.). Cultura, substantivo plural. Rio de Janeiro: CCBB / 34 Letras, 1996. p. $159-176$.

GUATTARI, F. Da produção de subjetividade. In: PARENTE, A. (Org.). Imagemmáquina: a era das tecnologias do virtual. São Paulo: Editora 34, 1993. p. 177191. 
GUATTARI, F. As três ecologias. Campinas: Papirus, 2004.

GUATTARI, F.; ROLNIK, S. Micropolíticas: cartografias do desejo. Petrópolis: Vozes, 2005.

GUMBRETCH, H. U. Produção de presença: o que o sentido não consegue transmitir. Rio de Janeiro: Contraponto/PUC-Rio, 2010.

HARAWAY, D.J. Simians, cyborgs, and women: the reinvention of nature. Nova Iorque: Routledge, 1991.

HARDT, M.; NEGRI, A. Império. Rio de Janeiro: Record, 2006.

HARDT, M.; NEGRI, A. Multidão: guerra e democracia na era do Império. Rio de Janeiro: Record, 2005.

HARVEY, D. A condição pós-moderna: uma pesquisa sobre as origens da mudança cultural. São Paulo: Loyola, 2003.

INGOLD, T. The perception of the environment. London: Routledge, 2000.

JACKSON, A. Anthropology at home. Nova Iorque: Tavistock, 1987.

JULLIEN, F. Um sábio não tem idéia. São Paulo: Martins Fontes, 2000.

JULLIEN, F. De lo universal, de lo uniforme, de lo común y del diálogo entre las culturas. Madrid: Siruela, 2010.

JULLIEN, F. Philosophie du vivre. Paris: Gallimard, 2011.

KOYRÉ, A. Do mundo fechado ao universo infinito. São Paulo: Forense, 1979.

KUZUMA, M.; LAFUENTE, P.; OSBORNE, P. The state of things. London: Koening Books, 2012.

LAPLANTINE, F. Quand le moi devient autre: connaître, partager, transformer. Paris: CNRS, 2012.

LATOUR, B. Jamais fomos modernos. São Paulo: Editora 34, 1994.

LATOUR, B. Reflexão sobre o culto moderno dos deuses fe(i)tiches. Bauru, SP: Edusc, 2002.

LATOUR, B. Reassembling the social: an introduction to Actor-Network-Theory. UK: Oxford University Press, 2005. 
LATOUR, B. Changer de société: refaire de la sociologie. Paris: La Découverte, 2006.

LATOUR, B. "A cautious Prometheus? A few steps towards a philosophy of design (with a special attention to Peter Sloterdijk)". Keynote lecture, Seminário Networks of Design. Cornwall, 2008. Disponível em: <http://www.bruno-latour. $\mathrm{fr} / \mathrm{sites} /$ default/files/112-DESIGN-CORNWALL-GB.pdf>. Acesso em: 03 fev. 2013.

LATOUR, B. Tarde's Idea of quantification. In: CANDEA, M. (Ed.). The social after Gabriel Tarde: debates and assessments. London: Rutledge, 2010. p. 145162.

LATOUR, B. La societé comme possession: la "preuve par l'orchestre". In: DEBAISE, D. Philosophies de la possession - Anthologie. Dijon: Les Presses Du Réél, 2011. Disponível em: <http://www.bruno-latour.fr/sites/default/files/119DEBAISE-POSSESSION-FR.pdf>. Acesso em: 13 abr. 2013.

LATOUR, B. Enquête sur les modes d'existence. Une anthropologie des modernes. Paris: La Decouverte, 2012. E "livro aumentado" disponível em: <http://www. modesofexistence.org/index.php/site/index>. Acesso em: 22 jan. 2013.

LAZZARATO, M. As revoluções do capitalismo. Rio de Janeiro: Civilização Brasileira, 2006.

LEPECKI, A. Agotar la danza: performance y política del movimiento. Barcelona: Mercat de les Flors, 2009. Colección Cuerpo de Letra, v. 1: Danza y Piensamiento.

LÉVI-STRAUSS, C. O pensamento selvagem. Campinas: Papirus, 1997.

LOUPPE, L. Corpos híbridos. In: SOTER, S.; PEREIRA, R. (Org.). Lições de Dança 2. Rio de Janeiro: UniverCidade, 2000. p. 27-40.

LOUPPE, L. Poétique de la danse contemporaine. Bruxelas: Contredanse, 1997.

LOUPPE, L. Poétique de la danse contemporaine: la suite. Bruxelas: Contredanse, 2007.

MARCUS, G. O intercâmbio entre arte e antropologia: como a pesquisa de campo em artes cênicas pode informar a reinvenção da pesquisa de campo em antropologia. Revista de Antropologia, São Paulo, v. 47, n. 1, p. 133158, 2004. Disponível em: <http://www.scielo.br/scielo.php?script=sci arttext\&pid=S0034-77012004000100004>. Acesso em: 22 jan. 2013. 
MATURANA, H.; VARELA, F. A árvore do conhecimento: as bases biológicas da compreensão humana. São Paulo: Palas Athena, 2001.

MATURANA, H.; VARELA, F. Autopoiesis and cognition. Boston: D. Reidel, 1980.

MASSUMI, B. Parables for the virtual: movement, affect, sensation. Durham: Duke University Press, 2002.

MAUSS, M. Ensaio sobre a dádiva: a forma e a razão da troca nas sociedades arcaicas (1924). In: 1974. v. 2, p. 37-178. . Sociologia e antropologia. São Paulo: EPU/ EDUSP,

MAUSS, M. Manual de etnografia. Lisboa: Dom Quixote, 1993.

MAUSS, M.; HUBERT, H. Esboço de uma teoria geral da magia (1903). In: . Sociologia e antropologia. São Paulo: EPU/EDUSP, 1974. v. 1, p. 37-176.

MERLEAU-PONTY, M. Fenomenologia da percepção. São Paulo: Martins Fontes, 1999.

ORTEGA, F. Amizade e estética da existência em Foucault. São Paulo: Graal, 1999.

PELBART, P. P. Vida Capital. São Paulo: Iluminuras, 2003.

PERLONGHER, N. O negócio do michê: a prostituição viril em São Paulo. São Paulo: Brasiliense, 1987.

PIETTE, A. De l'ontologie en anthropologie. Paris: Berg, 2012.

POE, E. A. Os crimes da Rua Morgue. In: . Manuscrito encontrado numa garrafa e outros contos. Rio de Janeiro: Ediouro, 1996. p. 1-22.

POLANYI, K. A grande transformação: as origens da nossa época. Rio de Janeiro: Campus, 1980.

POPPER, K. O mito do contexto. Lisboa: Edições 70, 1999.

RABINOW, P. Representações são fatos sociais: modernidade e pós-modernidade na antropologia. In: BIEHL, J. G. (Org. e trad.). Antropologia da Razão: ensaios de Paul Rabinow. Rio de Janeiro: Relume-Dumará, 1999a. p. 71-107. 
RABINOW, P. Artificialidade e iluminismo: da sociobiologia à biossociabilidade. In: BIEHL, J. G. (Org. e trad.) Antropologia da Razão: ensaios de Paul Rabinow. Rio de Janeiro: Relume-Dumará, 1999b. p. 135-157.

RANCIÈRE, J. Le destin des images. Paris: La Fabrique, 2003.

RANCIÈRE, J. Sobre políticas estéticas. Barcelona: Universitat Autônoma de Barcelona/ Museu d'Art Contemporani de Barcelona, 2005.

RANCIÈRE, J. Le maître ignorant. Paris: Fayard, 1987.

RANCIÈRE, J. A partilha do sensivel: estética e política. São Paulo: Ed. 34, 2005.

RANCIÈRE, J. O espectador emancipado. Lisboa: Orfeu Negro, 2010a.

RANCIÈRE, J. A comunidade como dissentimento. In: DIAS, B.; NEVES, J. (Coord.) A política dos muitos. Lisboa: Fundação EDP / Tinta da China, 2010b. p. $425-436$.

RORTY, R. Una ética para laicos. Madrid: Katz, 2009.

SAHLINS, M. A tristeza da doçura, ou a antropologia nativa da cosmologia ocidental. In: . Cultura na prática. Rio de Janeiro: UFRJ, 2004a. p. 563-619.

SAHLINS, M. Esperando Foucault, ainda. São Paulo: CosacNaify, 2004b.

SEARLE, J. Intencionalidade: um ensaio de filosofia da mente. Lisboa: Relógio d'água, 1999.

SENNET, R. O artifice. Rio de Janeiro/São Paulo: Record, 2009.

SENNET, R. Juntos: os rituais, os prazeres e a política da cooperação. Rio de Janeiro/São Paulo: 2012.

SERRES, M. Filosofia Mestiça: le tiers-instruit. Rio de Janeiro: Nova Fronteira, 1993.

SIMONDON, G. Dos lecciones sobre el animal y el hombre. Buenos Aires: La Cebra, 2008.

SIMONDON, G. L'individu et sa genèse physico-biologique. Paris: PUF, 1964.

SIMONDON, G. L'individuation psychique et collective. Paris: Aubier, 1989. 
SLOTERDJIK, P. La mobilisation infinie. Paris: Christian Bourgeois, 2000.

SLOTERDJIK, P. Le palais de cristal: à l'intérieur du capitalisme planétaire. Paris: Maren Sell Éditeurs, 2006a.

SLOTERDIJK, P. Esferas: Burbujas. Madrid: Siruela, 2003a. v. 1.

SLOTERDIJK, P. Esferas: Globos. Madrid: Siruela, 2003b. v. 2.

SLOTERDIJK, P. Esferas: Espumas. Madrid: Siruela, 2006b. v. 3.

SONTAG, S. Contra a interpretação. Porto Alegre: LP\&M, 1987.

STRATHERN, M. The concept of society is theoretically obsolete. In: INGOLD, T. (Ed.). Key debates in anthropology. London: Routledge, 1996.

STRATHERN, M. Partial Connections. Maryland: Rowman \& Littlefield, 1991. STRATHERN, M. O gênero da dádiva. Campinas: Unicamp, 2006.

SZTUTMAN, R. (Org.). Encontros com Eduardo Viveiros de Castro. Rio de Janeiro: Azougue, 2008.

TARDE, G. Monadologia e Sociologia. Petrópolis: Vozes, 2003.

TARDE, G. Les lois de l'imitation. Paris: Kime, 1993.

TARDE, G. A opinião e as massas. São Paulo: Martins Fontes, 1992.

THEMUDO, T. Gabriel Tarde: sociologia e subjetividade. Rio de Janeiro: Relume-Dumará, 2002.

URRY, J. Sociology beyond societies: mobilities for the twenty-first century. London: Routledge, 2000.

VELHO, O. Os novos sujeitos sociais. Revista Crítica de Ciências Sociais, [S.1.], n. 32, p. 119-127, jun. 1991.

VIANA VARGAS, E. Antes Tarde do que nunca: Gabriel Tarde e a emergência das ciências sociais. Rio de Janeiro: Contracapa, 2000.

VIVEIROS DE CASTRO, E. A inconstância da alma selvagem. São Paulo: Cosac\&Naify, 2002a. 
VIVEIROS DE CASTRO, E. O nativo relativo. Mana: Estudos de Antropologia Social, Rio de Janeiro, v. 8, n. 1, p. 113-148, abr. 2002b.

VIVEIROS DE CASTRO, E. A floresta de cristal. Coleções de espíritos e outros temas de antropologia serial. Conferência realizada na Casa de Ruy Barbosa, Rio de Janeiro, 2006.

VIVEIROS DE CASTRO, E. Metafisicas canibales: líneas de antropologia postestructural. Madrid: Katz, 2010.

VON KLEIST, H. Sobre o teatro de marionetas. Lisboa: Antígona, 2009.

WAGNER, R. The invention of culture. Chicago: The University of Chicago Press, 1981.

ZIZEK, S. A subjectividade por vir: ensaios críticos sobre a voz obscena. Lisboa: Relógio D’Água, 2006.

ZOURABICHVILI, F. Deleuze: une philosophie de l'evénement. Paris: PUF, 1996.

Recebido em: 05 de maio de 2013

Aceito em: 10 de julho de 2013 